\title{
MODULEMA Revista Científica sobre Diversidad Cultural
}

\section{EDUCACIÓN EN COMPETENCIAS INTERCULTURALES PARA LA DIVERSIDAD CULTURAL, ÉTNICA Y SEXUAL. LA EXPERIENCIA DEL PROYECTO “CINEDUKA” EN ESCUELAS BÁSICAS CHILENAS}

\author{
EDUCATIÓN IN INTERCULTURAL COMPETENCIES FOR SEXUAL, ETHNIC AND CULTURAL \\ DIVERSITY. THE CASE OF THE “CINEDUKA” PROJECT IN CHILEAN PRIMARY SCHOOLS
}

\author{
Mela-Contreras, José
}

Universidad de O’Higgins. Instituto de Ciencias de la Educación. Chile

Recibido | Received: 10/04/2020

Aprobado | Approved: 17/06/2020

Publicado | Published: 10/07/2020

Correspondencia | Contact: José Mela-Contreras | jose.mela@uoh.cl

(iD) 0000-0003-1192-4519

\section{RESUMEN}

Palabras clave

Educación intercultural

Diversidad cultural

Diálogo intercultural

Herramientas

audiovisuales

\section{Keywords}

Intercultural education

Cultural diversity
El presente artículo aborda la experiencia del proyecto de Investigación-acción "Cineduka" realizado con un grupo de docentes de Artes Visuales e Historia, quienes se desempeñan en el nivel de $7^{\circ}$ básico de escuelas públicas de la región de O'Higgins, Chile. Se realizaron reuniones de trabajo, capacitaciones y acompañamientos en el aula que contemplaron como principales recursos pedagógicos, el visionado de cine y la creación audiovisual del estudiantado, con el objetivo de desarrollar competencias interculturales, tales como reflexión intercultural y diálogo, en dos asignaturas del currículo chileno, para favorecer nuevos aprendizajes sobre lo diverso en la escuela y la sociedad.

Los principales resultados revelan que tanto estudiantes como docentes valoran el enfoque intercultural para incorporar en sus clases, identificando la temática como cercana y contingente. El visionado de cine y la creación audiovisual posibilitaron el pensamiento reflexivo, el diálogo y la movilización de emociones en el estudiantado por lo que se concluye que la metodología implementada por "Cineduka" conforma una propuesta pedagógica innovadora que puede aportar en el establecimiento de competencias interculturales en el profesorado y estudiantado, apuntando a la necesidad de flexibilizar las metodologías y procesos de enseñanza del sistema escolar chileno.

\section{ABSTRACT}

This paper discusses the Action-Research Project "Cineduka", which was carried out by a group of teachers of Visual Arts and History who teach at 7th grade in public schools in the Region of O'Higgins, Chile. To this end we held work meetings, training sessions and in-class teaching support, whose main 
Mela-Contreras, J. (2020). Educación en competencias interculturales para la diversidad cultural, étnica y sexual. La experiencia del proyecto "Cineduka" en escuelas básicas chilenas. MODULEMA, 4, 24-41. DOI: http://dx.doi.org/10.30827/modulema.v4i015156

Intercultural dialogue

Audiovisual Aids pedagogical resources included the visualization of films and the audiovisual creation by students. The goal was to develop intercultural competences such as dialoguing and intercultural reflection in two courses of the Chilean curriculum, thus promoting new learnings about diversity at school and society.

The main results reveal that both students and teachers praise the intercultural approach and include it in their teaching practices, considering this topic as close and necessary. In this line, film visualization and audiovisual creation allowed for reflective thinking, dialogue and emotion activation in students.

We conclude that the methodology implemented by "Cineduka" realizes an innovative pedagogical proposal that may contribute to developing intercultural competences in teachers and students, which tackles the need for flexible methodologies and teaching processes in the Chilean schooling system.

\section{INTRODUCCIÓN}

\section{Interculturalidad y diversidad en el sistema escolar chileno}

La interculturalidad se define como una teoría que aborda los procesos de comunicación e interacción entre los/as sujetos, de manera de ofrecer una respuesta a las diferentes problemáticas que surgen en el ámbito de la diversidad cultural (Stefoni, Stang y Riedemann, 2016). A diferencia de la multiculturalidad que refiere a la diversidad cultural y la convivencia de estudiantes con diferentes orígenes étnicos en las escuelas (Jiménez y Fardella, 2015), lo intercultural se propone como un enfoque capaz de intervenir en los procesos de convivencia entre los y las estudiantes, de modo de fomentar una actitud crítica hacia las asimetrías sociales y culturales que impiden un respeto y valoración de lo diverso. Por este motivo, el Ministerio de Educación define lo intercultural como un "proyecto ético-político (...) [capaz de generar] puentes de comunicación y diálogo entre las distintas culturas que comparten un territorio y una sociedad desde un plano de horizontalidad” (MINEDUC, 2017, p. 41).

En Chile, la construcción de una educación desde un enfoque intercultural ha permanecido ligada, desde la década de los noventa, al Programa de Educación Intercultural Bilingüe, esto es, un programa de enseñanza dirigido a niños y niñas indígenas y, principalmente, mapuches (Riedemann, 2008; Donoso, A., Contreras, R.; Cubillos, L. \& Aravena, L., 2006; MINEDUC, 2011; Lagos, 2015; Ibáñez, N. \& Druker, S., 2018; y Treviño, E., Morawietz, L., Villalobos, C. \& Villalobos, E., 2018). La interculturalidad, por ende, se asocia con la implementación de una iniciativa que busca fortalecer la identidad étnica de niños/as indígenas (Riedemann, 2008) para facilitar su "acceso al conocimiento y el éxito escolar” (Rozas, 2019, p.3). 
Mela-Contreras, J. (2020). Educación en competencias interculturales para la diversidad cultural, étnica y sexual. La experiencia del proyecto "Cineduka" en escuelas básicas chilenas. MODULEMA, 4, 24-41. DOI: http://dx.doi.org/10.30827/modulema.v4i015156

Actualmente, los desafíos educacionales se focalizan en la necesidad de ampliar este concepto a otros ámbitos igualmente relevantes, tales como la diversidad cultural y sexual, con el objetivo de incorporar a la población escolar inmigrante y LGBT (Ferrada, 2017). Estos desafíos están más acordes con una mayor presencia de estudiantes inmigrantes en las aulas chilenas (INE, 2017, 2018) provenientes de países sudamericanos y centroamericanos, como Haití, Venezuela y Colombia ${ }^{1}$, presencia que genera tensiones, debido al incremento de actitudes discriminatorias y racistas. En Chile, se evidencian conductas de rechazo, acoso y/o discriminación hacia estudiantes de enseñanza básica y media por su nacionalidad (Berrios y Palou, 2014), condición sexual y de género (MINEDUC, 2013; Cornejo, 2018), pero también por su origen étnico (UNICEF, 2014a; 2014b), incluyendo el color de su piel (Meus, González \& Manzi, 2016).

\section{Competencias interculturales como el diálogo y la reflexión para fomentar el res- peto hacia la diversidad étnica, cultural y sexual}

De acuerdo con lo anterior, la Organización de las Naciones Unidas ha manifestado su preocupación por la "persistente discriminación contra pueblos indígenas, personas lesbianas, gays, bisexuales y transgénero, migrantes (...) en los ámbitos laboral y educativo" (ONU, 2015, p. 4), estableciendo la necesidad de planificar estrategias y metodologías de enseñanza dialógicas, capaces de contrarrestar la violencia y favorecer la construcción de valores, actitudes y capacidades positivas hacia los derechos humanos, incluidos los derechos sexuales.

En este sentido, la UNESCO (2017) ha propuesto la promoción y enseñanza de competencias interculturales, tales como el diálogo intercultural, el respeto y humildad cultural, de manera de poner en juego la razón, emoción y creatividad para encontrar significados y comprensiones compartidos de una ciudadanía que reconoce y valora la diferencia cultural. La enseñanzaaprendizaje de estas competencias consiste en dotar de herramientas sociales y afectivas a niñas y niños, promoviendo en término amplio, la cohesión y armonía social, contrarrestando la fragmentación y exclusión social.

Al respecto, múltiples autores enfatizan que la incorporación del diálogo en la enseñanza desarrolla la capacidad de reflexión crítica entre docentes y estudiantes (Freire, 1970, 2004, 2015; Dysthe, Bernhardt \& Esbjørn, 2013; Skidmore \& Murakami, 2016). Gracias a esta reflexión es posible fijar una posición epistemológica y un rol docente más activo en materia intercultural que apunte a una transformación personal y social, con la aspiración de ganar en cambio y justicia social. Así entendida, una educación basada en el diálogo y reflexión intercultural describe un proceso de enseñanza-aprendizaje más horizontal y participativo entre docentes y educandos, con el fin de fomentar una profunda comprensión de la realidad

1. El Ministerio de Educación de Chile informa un incremento de un 1,3\% de estudiantes extranjeros entre los años 2015 a 2017. 
Mela-Contreras, J. (2020). Educación en competencias interculturales para la diversidad cultural, étnica y sexual. La experiencia del proyecto "Cineduka" en escuelas básicas chilenas. MODULEMA, 4, 24-41. DOI: http://dx.doi.org/10.30827/modulema.v4i015156

(Skidmore y Murakami, 2016), en este caso, una realidad compuesta por una sociedad caracterizada por una gran diversidad y multiculturalidad.

\section{Cine y creación audiovisual escolar en asignaturas como Artes e Historia para edu- car en competencias interculturales}

El cine, tal como afirma Olivieri (2016 en Gutiérrez y Molina, 2019), es una herramienta educativa muy útil para "desarrollar y potenciar la educación intercultural, [mediante] una cuidada selección de películas, (...) para formar al alumnado en distintas conductas y valores, que sirvan de reflexión tras su visionado" (p.81). De esta forma, la utilización de sesiones fílmicas puede funcionar como una plataforma adecuada para facilitar la discusión y análisis de problemáticas vinculadas a la importancia de convivir en un ambiente de respeto hacia la diversidad.

En concordancia con la UNESCO (2017), una educación intercultural basada en competencias interculturales requiere de metodologías de enseñanza capaces de potenciar que el estudiantado integre nuevas concepciones sobre la diversidad, superando ideas previas que pueden ser erradas y basadas en prejuicios negativos o actitudes discriminatorias. El profesorado puede generar nuevos procesos de construcción de significado sobre el valor de la diversidad para una mejora de la vida social y cultural de sus estudiantes.

Una metodología que use el visionado de cine y creación audiovisual puede tomar como referencia las bases curriculares de la enseñanza básica en Chile que, a través de materias como las Artes Visuales e Historia, Geografía y Ciencias Sociales, incorpora conceptos vinculados a la diversidad en sus objetivos de aprendizaje. Asimismo, el Arte y la Historia conforman dos ámbitos del conocimiento que aproximan a los/as educandos al estudio, exploración y revisión de los diferentes "estilos de vida, modos de vivir juntos, sistemas de valores, tradiciones y creencias" (UNESCO 2017, p. 14) de la humanidad.

Ver cine y crear producciones audiovisuales puede ser considerado un medio de expresión de las identidades y preocupaciones, ideas e ideales estudiantiles; a través del lenguaje audiovisual es posible que docentes y estudiantes se involucren en acciones educativas y creativas que intervengan la realidad. Tomando como referencia a Atkinson (2018), el uso de metodologías basadas en el uso del cine puede facilitar que el alumnado se cuestione por las relaciones de poder y asimetrías socioculturales que afectan a minorías étnicas, culturales y sexuales en la sociedad, fomentando relaciones más empáticas, democráticas y afectivas entre los sujetos.

\section{La experiencia de "Cineduka"}

En este contexto, el proyecto "Cineduka": cine e interculturalidad en el aula de Enseñanza Básica” realizado en escuelas públicas de la VI región, se propuso desarrollar una metodología 
Mela-Contreras, J. (2020). Educación en competencias interculturales para la diversidad cultural, étnica y sexual. La experiencia del proyecto "Cineduka" en escuelas básicas chilenas. MODULEMA, 4, 24-41. DOI: http://dx.doi.org/10.30827/modulema.v4i015156

pedagógica innovadora basada en el diálogo y la reflexión crítica con herramientas del cine, para transformar actitudes y conductas asociadas a la discriminación al y rechazo en el aula.

Desde la investigación-acción se diseñó una propuesta de enseñanza intercultural abogando por que el profesorado asumiera el rol de agentes interculturales activos, capaces de propiciar y/o potenciar aprendizajes desde una perspectiva de transformación positiva y favorable a la valoración de la diversidad cultural, étnica y sexual, contrarrestando actitudes como el racismo y la xenofobia

La investigación-acción que implicó el desarrollo de la propuesta "Cineduka", se conformó de las siguientes acciones:

- Reuniones de trabajo con directivos y profesorado participante.

- 4 jornadas de capacitación docente/ análisis y visionado de cine.

- Talleres "Cineduka” en el aula con Visionado de cine y Creación audiovisual de los/ as estudiantes

- Reuniones de trabajo con el profesorado.

Revisaremos los principales lineamientos metodológicos de esta investigación- acción, y un análisis realizado en base a bitácoras de observación y entrevistas semiestructuradas aplicadas al alumnado y profesorado, con el fin de:

- Conocer el impacto pedagógico y el desarrollo de competencias interculturales entre estudiantes de $7^{\circ}$ año básico, a partir de la implementación del aprendizaje dialógico, visionado de cine y creación audiovisual.

\section{MATERIAL Y MÉTODO}

\section{Diseño de la investigación}

El diseño de investigación fue de carácter cualitativo. En particular se trabajó desde la investigación-acción (Montero, 2006; Colmenares \& Piñeiro, 2008 y McIntyre, 2008), con el propósito de construir múltiples significados entre los/as sujetos sobre la importancia de una educación intercultural basada en competencias interculturales.

La metodología usada se representa en la siguiente ilustración:

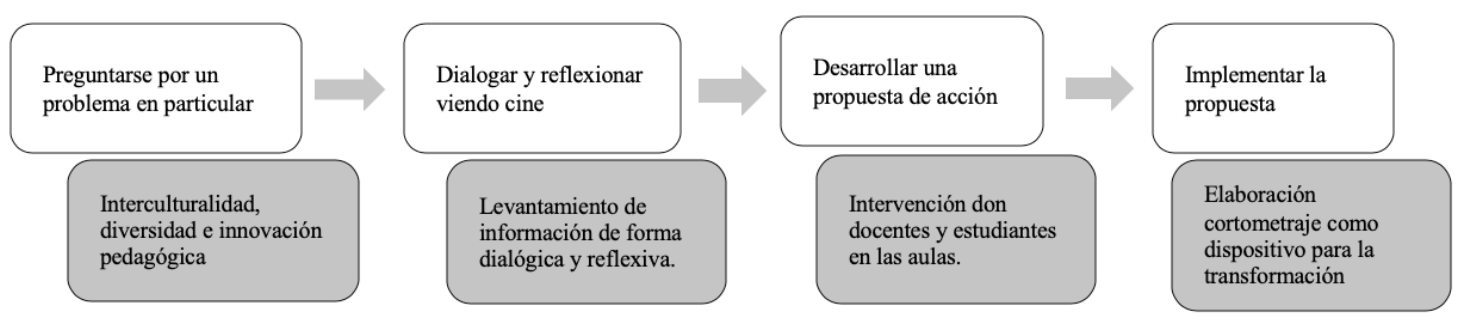

Ilustración 1. Metodología del proyecto 
Mela-Contreras, J. (2020). Educación en competencias interculturales para la diversidad cultural, étnica y sexual. La experiencia del proyecto "Cineduka" en escuelas básicas chilenas. MODULEMA, 4, 24-41. DOI: http://dx.doi.org/10.30827/modulema.v4i015156

\section{Población y muestra}

La investigación se desarrolló en la VI región de O’Higgins, Chile, la cual posee rasgos demográficos multiculturales. La población regional es de 780.627 habitantes, de las cuales 54.873 personas poseen origen indígena y 13.241 personas corresponden a inmigrantes internacionales (INE, 2019)².

Las cinco escuelas participantes, ubicadas en diferentes comunas, respondieron a una invitación del Instituto de Ciencias de Educación de la Universidad de O'Higgins, de un total de diez establecimientos convocados. La selección de las escuelas tuvo como criterios: pertenecer al sector público, estar inserta en una comuna urbana o rural con población migrante entre su fuerza de trabajo y no tener un programa de educación intercultural ejecutándose.

Tabla 1. Características de la población

\begin{tabular}{ccccc}
\hline $\begin{array}{c}\text { Establecimiento/ } \\
\text { Escuela }\end{array}$ & $\begin{array}{c}\text { Matrícula total } \\
\text { estudiantes }\end{array}$ & $\begin{array}{c}\mathbf{N}^{\circ} \text { de alumnos/as } \\
\text { inmigrantes en E. } \\
\text { básica }\end{array}$ & $\begin{array}{c}\text { Concentracfión } \\
\text { alumnos/as } \\
\text { prioritarios }\end{array}$ & Urbano/Rural \\
\hline 1 & 247 & 30 & $65 \%$ & Urbano \\
2 & 584 & 43 & $67 \%$ & Urbano \\
3 & 279 & 1 & $67 \%$ & Rural \\
4 & 194 & 4 & $82 \%$ & Rural \\
5 & 316 & 5 & $67 \%$ & Rural \\
\hline
\end{tabular}

Nota: Elaboración propia en base a datos online de cada Municipio e información aportada por los/as directivos de cada establecimiento.

El cuerpo docente que asistió a los talleres "Cineduka" estuvo conformado por once docentes que ejercían en las asignaturas de Artes Visuales e Historia, Geografía y Ciencias Sociales para $7^{\circ}$ año de Enseñanza Básica. Cabe señalar que la mayoría del profesorado no era especialista en ambas materias, sino docentes de Enseñanza Básica con horario asignado en las áreas. La composición de la muestra se presenta en la siguiente tabla:

Tabla 2. Composición de la muestra

\begin{tabular}{ccc}
\hline Establecimiento/ Escuela & Docentes participantes & Alumnado de 7mo. Básico \\
\hline $\mathrm{N}^{\circ} 1$ & 2 & 20 \\
$\mathrm{~N}^{\circ} 2$ & 3 & 30 \\
$\mathrm{~N}^{\circ} 3$ & 2 & 35 \\
$\mathrm{~N}^{\circ} 4$ & 2 & 25 \\
$\mathrm{~N}^{\circ} 5$ & 2 & 35 \\
Total participantes & 11 & 145 \\
\hline
\end{tabular}

Nota: Elaboración propia.

2. Datos del Instituto Nacional de Estadísticas (2019). Fuente: https://regiones.ine.cl/documentos/ default-source/region-vi/banco-datos-r6/resultados-censo-2017/informe-con-fichas-comunales-ohiggins---tomo-3-mapas-de-la-inmigración-internacional.pdf?sfvrsn=5984d4ed 4 
Mela-Contreras, J. (2020). Educación en competencias interculturales para la diversidad cultural, étnica y sexual. La experiencia del proyecto "Cineduka" en escuelas básicas chilenas. MODULEMA, 4, 24-41. DOI: http://dx.doi.org/10.30827/modulema.v4i015156

\section{Procedimiento}

A raíz de las reuniones de trabajo iniciadas con el profesorado se definieron tres acciones a seguir durante el desarrollo del proyecto:

1. Realización de talleres de capacitación docente.

2. Acompañamiento en el aula que implicó visionado de cine.

3. Acompañamiento en el aula que implicó la creación audiovisual del estudiantado respecto a las temáticas abordadas con los docentes.

Como se puede apreciar en la Tabla 3, la capacitación docente se organizó en dos módulos: uno teórico en el que se revisó y discutió bibliografía, conceptos y experiencias internacionales sobre la importancia de la interculturalidad, las características del aprendizaje dialógico y su aplicación a través del visionado de cine.

Tabla 3. Módulos, docentes y horas de los talleres "Cineduka"

\begin{tabular}{|c|c|c|c|}
\hline Módulos teóricos & Académico/a & Horas presenciales & Formación \\
\hline $\begin{array}{c}\text { Educación } \\
\text { intercultural para } \\
\text { prevenir el racismo y } \\
\text { xenofobia }\end{array}$ & Andrea Riedemann & 9 & $\begin{array}{c}\text { Doctora en Ciencias } \\
\text { Históricas y Culturales, } \\
\text { U. de Berlín }\end{array}$ \\
\hline $\begin{array}{l}\text { Educación estética } \\
\text { e interculturalidad: } \\
\text { hacia una pedagogía } \\
\text { sensible }\end{array}$ & Leonora Beniscelli & 9 & $\begin{array}{c}\text { Doctoranda en } \\
\text { Sociología, U. Alberto } \\
\text { Hurtado }\end{array}$ \\
\hline Módulos prácticos & Académico/a & Horas presenciales & Formación \\
\hline $\begin{array}{c}\text { Cine e } \\
\text { interculturalidad en la } \\
\text { escuela } \\
\text { Introducción al cine } \\
\text { en el aula }\end{array}$ & José Mela (autor) & 9 & $\begin{array}{c}\text { Doctor en Arte y } \\
\text { Educación, U. de } \\
\text { Barcelona }\end{array}$ \\
\hline
\end{tabular}

Nota: Elaboración propia.

En el módulo práctico se revisaron los distintos filmes a utilizar, nacionales e internacionales, basados en temáticas interculturales que incluían la diversidad cultural, étnica y sexual. Asimismo, se analizó la relación entre los filmes y el currículo de las asignaturas, de manera de invitar al profesorado a innovar en sus planificaciones de clase, creando una secuencia didáctica que incorporara el visionado de algunas o todas las películas, el trabajo dialógico y reflexivo y una posterior elaboración de producciones audiovisuales escolares.

Los filmes visionados por el profesorado y estudiantado en los talleres (tabla 4) fueron elegidos según los siguientes criterios: a) representar una diversidad cultural, étnica y sexual, b) su corta duración (a excepción de "Binta y la gran idea”), y c) ser accesibles mediante YouTube. 
Mela-Contreras, J. (2020). Educación en competencias interculturales para la diversidad cultural, étnica y sexual. La experiencia del proyecto "Cineduka" en escuelas básicas chilenas. MODULEMA, 4, 24-41. DOI: http://dx.doi.org/10.30827/modulema.v4i015156

Asimismo, se pusieron a disposición del profesorado fichas pedagógicas con los enlaces para su reproducción y datos como: director-a, año, temática, duración y breve resumen de cada filme.

Tabla 4. Filmes visionados por el profesorado y alumnado en los talleres "Cineduka"

\begin{tabular}{|c|c|c|c|c|}
\hline Título & Dirección & País, año & Temática & Minutos \\
\hline $\begin{array}{c}\text { "Binta y la gran } \\
\text { ideal" }\end{array}$ & Javier Fresser & Senegal, 2004 & Género & 32 \\
\hline “Express” & $\begin{array}{c}\text { Juan Herreros y } \\
\text { Carlos Olalla }\end{array}$ & España, 2017 & $\begin{array}{l}\text { Racismo, } \\
\text { xenofobia }\end{array}$ & 13 \\
\hline "Vestido nuevo" & Segi Pérez & España, 2008 & Diversidad & 13 \\
\hline “Hijab” & Xavi Sala & España, 2005 & Diversidad & 8 \\
\hline "We tripantu" & Uchilelndígena & Chile, 2016 & Inclusión & 4 \\
\hline
\end{tabular}

Nota: Elaboración propia.

\section{Proceso de levantamiento de información}

En distintas fases del proyecto (reuniones con docentes, capacitaciones y acompañamiento pedagógico en el aula), se utilizó la técnica de notas de campo para registrar diálogos, reflexiones y hechos de interés investigativo. En la etapa final del acompañamiento se aplicaron entrevistas semi-estructuradas al profesorado (11 en total) y a un número determinado de estudiantes (32), con el fin de conocer el impacto pedagógico de las herramientas trabajadas con los/as docentes en la promoción de competencias interculturales entre estudiantes de $7^{\circ}$ año básico.

\section{Análisis de los datos}

Tanto las entrevistas realizadas a los/as participantes como las observaciones y notas de campo efectuadas por los investigadores se sistematizaron mediante una matriz de análisis de contenido que fue evidenciando alcances del proyecto a lo largo de su desarrollo, así como desafíos y posibilidades ${ }^{3}$.

La matriz se construyó en base a las siguientes unidades de análisis: Se presentan algunas de las categorías y subcategorías utilizadas a modo resumen:

Tabla 5. Unidades de análisis y principales categorías

\section{Unidad $\mathrm{n}^{\circ}$ 1: El estudiantado}

\section{Categorías: \\ Subcategorías}

Visionado de cine en el aula Interés y disposición con la metodología La interculturalidad como temática

Creación audiovisual

3. Debido a criterios prácticos, como la cantidad de datos manejados, se realizó un análisis manual prescindiendo de software de análisis cualitativo. 
Mela-Contreras, J. (2020). Educación en competencias interculturales para la diversidad cultural, étnica y sexual. La experiencia del proyecto "Cineduka" en escuelas básicas chilenas. MODULEMA, 4, 24-41. DOI: http://dx.doi.org/10.30827/modulema.v4i015156

\begin{tabular}{ll}
\hline Unidad $\mathrm{n}^{\circ}$ 2: El profesorado & \\
\hline Categorías: & Subcategorías \\
Cine en el aula & Valoraciones \\
Dificultades para flexibilizar su metodología & Herramientas pedagógicas \\
& Herramientas técnicas \\
& Diálogo y reflexión crítica \\
Los contenidos de la interculturalidad & Valoraciones \\
Limitaciones vinculadas al contexto educativo & Sobrecarga académica \\
& Infraestructura y materiales \\
& Rigidez metodológica \\
\hline Unidad ${ }^{\circ}$ 3: La propuesta metodológica “Cineduka” \\
\hline Categorías: & Subcategorías \\
Alcances del visionado de cine con la temática & Diálogo \\
estudiada & Reflexión crítica \\
& Movilización de emociones \\
La experiencia educativa & Necesidades de fortalecimiento docente/ Rol \\
& docente \\
& Proceso dinámico de enseñanza \\
& Disposición del estudiantado \\
\hline
\end{tabular}

Nota: Elaboración propia.

\section{Criterios de calidad, desafíos y posibilidades que abre el estudio}

Como criterios de calidad se contempló condiciones de rigor y sensibilidad en el contexto de estudio. En cuanto al rigor, la investigación se sometió a revisiones externas de otros investigadores/as principalmente en relación con la ejecución de la técnica Investigaciónacción. Sumado a ello, se realizó un acucioso registro de notas de campo y los resultados se sometieron a discusión con los/as docentes participante. El trabajo conjunto con el profesorado y la reflexividad crítica durante la circularidad del proceso investigativo potenciaron la sensibilidad del trabajo para el levantamiento de datos, cuestionamientos, resolución de problemas y evaluaciones.

Como criterios éticos se contempló una comunicación directa con los/as docentes participantes, y transparencia respecto al desarrollo de todas las acciones implementadas en la investigación.

Durante el desarrollo de "Cineduka" emergieron dificultades vinculadas al contexto educativo y al profesorado, en tanto este se evidencia con sobrecarga académica y, en ocasiones, poca disposición a flexibilizar su experiencia en el aula debido al cansancio o estrés. Estos factores pueden ser una limitante a la hora de implementar este tipo de acciones extracurriculares e, incluso, para la recolección de los datos y el trabajo en conjunto con los/as actores. Debido a esto, la técnica de investigación-acción no siempre se implementó de manera fluida, lo cual requirió de revisiones constantes por parte del investigador para no pasar por alto el parecer y las dificultades que tuvieron los/as docentes en el proceso. 
Mela-Contreras, J. (2020). Educación en competencias interculturales para la diversidad cultural, étnica y sexual. La experiencia del proyecto "Cineduka" en escuelas básicas chilenas. MODULEMA, 4, 24-41. DOI: http://dx.doi.org/10.30827/modulema.v4i015156

Interesados en recoger información sobre una experiencia práctica de innovación en el contexto educativo, este estudio sólo contempló recabar información con docentes y estudiantes. Por tanto, la investigación abre la necesidad de indagar también en distintos aspectos del sistema educativo chileno que posibilitan o limitan la inclusión de prácticas innovadoras en su dimensión cultural, política y económica.

\section{PRINCIPALES RESULTADOS}

\section{Valoración e interés por la interculturalidad}

En primer lugar, es importante señalar que, a través del acompañamiento docente y, luego, en las entrevistas, se constata que la gran mayoría del profesorado valoró la incorporación de un enfoque intercultural en sus clases de Arte e Historia, teniendo en cuenta que los/as docentes observaban en su trabajo cotidiano cómo estas actitudes generaban tensiones y dificultades para construir un clima de convivencia y aprendizaje más armónico.

Hoy se siente que los chiquititos hacen diferencia por la piel. En mi curso, el $4^{\circ}$, los niños hacen diferencia, dicen: no, es que tú eres la negra, no, es que es más negra que tú, y se miran la piel y se discriminan por eso (profesora 1, Escuela $n^{\circ} 1$ ).

Es muy importante la interculturalidad por todas estas diferencias que existen dentro de la sala de clase. Los chiquillos tienen que reflexionar sobre su actuar, entender que no es bueno el concepto de segregar, de discriminar, que en esta vida somos todos diferentes. Y no tanto físicamente, psicológicamente tenemos distintos pensamientos, distintas religiones, no podemos ser únicos $y$, por tanto, tenemos que aprender dentro de la sala de clases (...) Y en una familia, en un hogar, en una comunidad entera, yo creo que todos deberían aprender eso: el aceptar las diferencias (Profesora 1, Escuela $\left.n^{\circ} 1\right)$.

Por otro lado, el cuerpo docente destacó que el estudiantado mostrara gran disposición para el diálogo y sensibilidad hacia las temáticas presentadas en las películas. La evidente movilización de emociones que generaron los filmes y las problemáticas apreciadas, ofrecieron la oportunidad al profesorado de relacionar los conflictos fílmicos con el contexto sociocultural del alumnado, fomentando la reflexión y discusión a situaciones experimentadas en la escuela o cotidianidad estudiantil. Así lo revelan los siguientes testimonios:

Investigador: ¿Ellos encuentran relación entre lo que pasa en las películas con su experiencia? Profesor: si, yo creo que descifran mejor los mensajes cuando las situaciones se pueden vincular. La vinculación con su contexto es importante porque esa vinculación ya es una reflexión. La película Binta, [por ejemplo] se circunscribía a un contexto escolar en África, no era igual que este, pero a ellos/as ese lenguaje le hizo mucho sentido, y si ellos/as la relacionan con cosas que le suceden a ellos o a alguien de su entorno significa que ya reflexionaron (Profesor 10, Escuela $n^{\circ} 5$ ). 
Mela-Contreras, J. (2020). Educación en competencias interculturales para la diversidad cultural, étnica y sexual. La experiencia del proyecto "Cineduka" en escuelas básicas chilenas. MODULEMA, 4, 24-41. DOI: http://dx.doi.org/10.30827/modulema.v4i015156

Cuando [a los/as estudiantes] los llevamos a reflexionar, cuando los llevamos a cuestionar, a preguntarse, hace que comparen la realidad con el cine y que analicen: ¡esto es una visión! pero ¿hay más? Yo tengo que generar la mía (...). Muchas veces el cine te conmueve, te genera sensaciones, pero todas esas sensaciones o todas esas percepciones (...) hay que materializarla en alguna idea concreta, hay que llevarla a la realidad y, a partir de eso, cuestionar, generar dudas, consultas entre los estudiantes (profesor 3, Escuela n ${ }^{\circ}$ 2).

En relación con los filmes, es relevante señalar que "Binta y la gran idea" y "Vestido nuevo" que abordan temas como el derecho a la educación de las niñas del África y la transexualidad infantil en una escuela primaria española, resultaron ser películas muy atrayentes, pues motivó que algunas/os estudiantes buscaran más títulos con temáticas similares. El filme colombiano, "Sin decir nada" (2007), que explora la diversidad sexual en el sistema escolar formal es un ejemplo de ello. De este modo, constatamos que el cine con perspectiva intercultural contribuye a sensibilizar y ampliar la comprensión con respecto a temáticas vinculadas con la diversidad sexual, de forma tal que funciona como un marco referencial para educar sobre lo diverso (UNESCO, 2017). Los siguientes testimonios estudiantiles dan cuenta de esto:

Investigador: ¿Ustedes creen que lo que vieron en las películas se parece a lo que ustedes viven en sus vidas? Estudiantes piensan antes de responder y parecen tener dudas sobre la pregunta. Investigador: Por ejemplo," Vestido nuevo" con la transexualidad, "Binta" con la discriminación de género o "Hijab", al usar algo que a los demás les molesta... Estudiante 2: Si, eso se ve harto ahora en la actualidad. De las películas que vimos se ve harto en la actualidad lo de la discriminación, la transexualidad... Investigador: ¿Qué otras similitudes ven ustedes?

Estudiante 2: La similitud es que... una persona puede cambiar de un momento a otro. Por ejemplo, si una persona... por ejemplo en "Sin decir nada", no sé si las niñas eran lesbianas o bisexuales nadie lo sabía, entonces puede que alguien que nosotras conozcamos sea así y puede que nadie lo sepa. Y ser así no tiene nada de malo, ser diferente (Estudiantes, Escuela ${ }^{\circ} 3$ ).

Investigador: ¿Cuál fue la película que más te gustó y por qué? Estudiante 1: "Vestido nuevo" ... porque nos cuenta sobre la homosexualidad y lo que pasa en Chile y otros países y que no hay que discriminar. Estudiante 2: A mí me gustó "Binta y la gran idea", más que Vestido nuevo. Me gustó porque mostraba lo que pasaba hace muchos años, el machismo de acá en Chile, porque si nos recordamos tiempo atrás la mujer no podía ser presidenta, no tenía los mismos derechos que los hombres, entonces, se ve que es un país un poco más democrático y ha ido avanzando cada vez más en el sentido de la interculturalidad (Estudiantes, Escuela $n^{\circ} 4$ ).

\section{Visionado de cine y creación audiovisual: Hacia una metodología no tradicional}

Respecto al uso del cine como herramienta pedagógica, se constata que esta fomentó y facilitó el diálogo entre docentes y estudiantes sobre temáticas vinculadas al respeto por 
Mela-Contreras, J. (2020). Educación en competencias interculturales para la diversidad cultural, étnica y sexual. La experiencia del proyecto "Cineduka" en escuelas básicas chilenas. MODULEMA, 4, 24-41. DOI: http://dx.doi.org/10.30827/modulema.v4i015156

la diversidad cultural, étnica y sexual, por medio de una perspectiva reflexiva y crítica que abordó con profundidad temas como la discriminación y xenofobia. A su vez, el proceso de diálogo y reflexión entre docentes y estudiantes gatilló el interés y valoración del alumnado por realidades culturales y sociales diferentes a las suyas. En este sentido, ver cine, dialogar y reflexionar, en contraste con el uso de metodologías más tradicionales como la clase expositiva, contribuyó a construir un clima de aprendizaje más motivante en términos interculturales, para los/as educandos.

Los estudiantes están en silencio mientras ven "Vestido nuevo", con luz apagada... prestan mucha atención ( $\mathrm{y}$ es un curso bullicioso) ... algunos hacen comentarios entre ellos, murmurando. Terminada la película el profesor anota "competencias interculturales: diálogo, respeto, humildad” en la pizarra y pregunta: “¿Cuáles son los lentes con los que Mario ve el mundo?". Los estudiantes le miran como pensando. El filme ha provocado diferentes sensaciones y emociones en los estudiantes. El profesor insiste con las preguntas: ¿cuál de estas competencias estuvieron presentes? (muestra la pizarra). Estudiante 1: Yo creo que autoconciencia porque no lo respetaban por cómo se vistió. Estudiante 2: Yo respaldo lo que dice mi compañera porque nadie lo respetaba cuando él llega vestido de mujer (Diario de campo, Escuela n 5 ).

La clase se centra en describir qué es la migración (...) La profesora describe los efectos de la migración en Europa con "Alikome" (corto de YouTube) y la compara con el caso chileno. Un estudiante pregunta por qué solo han visto películas europeas y la profesora responde: "para graficar la situación de muchos inmigrantes que son víctimas a diario de prejuicios". Agrega que esto se ve en países como Brasil y Chile. Los estudiantes piden ver nuevamente el corto, pues algunos no entendieron bien de qué trata. Luego, la profesora pregunta: ¿todos entendieron bien el mensaje del corto? Los estudiantes responden que sí y empiezan a compartir opiniones sobre racismo. Profesora pregunta "¿quién se sintió impactado con lo que pasó? ¿o tiene alguna experiencia? ¿te han discriminado?" Los estudiantes declaran haber sufrido alguna discriminación por ser "más morenos", por "tener la piel oscura" y otros rasgos físicos que, afirman, se verbalizan en apodos cotidianos (Diario de campo, Escuela no 1).

Podemos desprender de lo anterior, que el visionado y discusión cinematográfica promueve, por un lado, un cambio a la clase convencional, es decir, una transformación entre una clase centrada en la figura del/la docente y transmisión pasiva de los contenidos por una clase con una comunicación mucho más fluida y significativa. Por otra parte, se evidencia la creación de situaciones pedagógicas donde el profesorado facilita/habilita nuevas formas de conocer y de construir un aprendizaje que sensibiliza sobre la diversidad. Bajo este rol docente ver cine en el aula no se limita a escuchar pasivamente un "supuesto "mensaje" cinematográfico" (Lifschitz, 2014, p. 167) o ilustrar contenidos; ver cine estimula la construcción de "diversas lecturas sobre una misma realidad, contribuyendo así a desarrollar una perspectiva crítica" (p. 167) de los temas visionados. Testimonios de estudiantes a este respecto así lo describen: 
Mela-Contreras, J. (2020). Educación en competencias interculturales para la diversidad cultural, étnica y sexual. La experiencia del proyecto "Cineduka" en escuelas básicas chilenas. MODULEMA, 4, 24-41. DOI: http://dx.doi.org/10.30827/modulema.v4i015156

Investigador: ¿Ustedes reflexionan cotidianamente con sus profesores y profesoras? Estudiante 1: No, casi siempre pasamos materia. Estudiante 2: Exacto. Estudiante 3: No hablamos. Estudiante 1: Igual sería bacán poder, quizás no toda la clase, porque igual tenemos que aprender, sino que en un momento pudiéramos dejar de escribir y hablar en torno a la materia (...) poner un poco de nosotros, dialogar más con los profesores. Estudiante 2: Qué entendemos o qué no entendimos porque, casi siempre: ya, iquién no entendió! (imita la voz de adulto enojado) $Y$ yo [soy la que] no entendí (ríe). No voy a levantar la mano, voy a quedar en vergüenza (Estudiantes, Escuela ${ }^{\circ}$ 3).

Investigador: ¿En la metodología de clase, ustedes dialogaron con sus profesores, hablaron la materia? Estudiantes 1, 2 y 3: Sí. Investigador: ¿hablan cotidianamente con sus profesores temas como estos, les gustó? Estudiante 1: yo opino que estuvo súper bueno porque había compañeros que no sabían lo que era la interculturalidad, entonces como teníamos que hacer un video que se tratara de la interculturalidad tuvimos que, en vez de que los profesores nos ayudaron a entender bien, mostrarlo con videos, con opinión de los compañeros también... (Estudiantes, Escuela $n^{\circ} 2$ ).

Resulta interesante que los/as estudiantes establezcan una diferencia entre dialogar, como un proceso donde ellos/as pueden poner en juego relatos y experiencias personales, y la clase misma, considerado como el mecanismo para aprender o cuando los/as docentes pasan la materia. Según Lifschitz (2014), esto se vincula con la oportunidad de que el estudiantado produzca su propio conocimiento sobre una temática escolar, en vez de actuar como meros receptores pasivos de información. Por otro lado, dialogar sobre temas ligados a la interculturalidad rompe el esquema de clase más tradicional, puesto que el profesorado invita a desarrollar una interpretación personal sobre los temas, en un proceso de construcción dialógica de significado donde "se asume que los significados [de la realidad] surgen y se desarrollan a través de la interacción personal” (Dysthe, Bernhardt y Esbjørn, 2013, p. 10).

En este proceso resulta especialmente relevante el rol asumido por los/as docentes, cual es, facilitar la discusión y reflexión como instancias para estrechar vínculos, valorando las opiniones de sus estudiantes. A este respecto, es preciso destacar que resultó complejo para el profesorado comprender cómo la construcción de un clima de enseñanza basado en la confianza, diálogo y escucha, se dificultaba por dos razones: a) los/a estudiantes no estaban acostumbrados a una clase íntegramente dialogada, sino más bien a seguir instrucciones, y b) una cierta resistencia docente para flexibilizar su quehacer pedagógico, ya que existía la noción de que sus prácticas pedagógicas habituales, centradas en la clase frontal, resultaban más efectivas para mantener la disciplina y el control de sus clases.

En relación con el proceso de creación estudiantil ${ }^{4}$ se constata el cumplimiento de dos propósitos: a) evocar nuevos significados sobre la diversidad, a partir de los aprendizajes

4. Se realizaron quince producciones audiovisuales, con un promedio de tres producciones por escuela 
Mela-Contreras, J. (2020). Educación en competencias interculturales para la diversidad cultural, étnica y sexual. La experiencia del proyecto "Cineduka" en escuelas básicas chilenas. MODULEMA, 4, 24-41. DOI: http://dx.doi.org/10.30827/modulema.v4i015156

escolares y b) levantar nuevas evidencias para la evaluación de estos aprendizajes, considerados como formativos. Este proceso de creación animó a los/as escolares a volcar su creatividad e intereses en la representación audiovisual, de manera tal que ningún/a docente tuvo grandes dificultades para que sus estudiantes organizaran sus tiempos y objetivos de trabajo.

El curso trabaja en la construcción de un guión en grupo, los grupos se conforman de 5 a 6 estudiantes. En general se manifiestan animados con la actividad, los dirigen los profesores 3 y 5 (Establecimiento $n^{\circ} 2$ ). Yo colaboro en la actividad porque es un grupo numeroso y se debe estar pendiente que todos trabajen y entiendan de qué se trata lo que se les pide. Los estudiantes se dividen los roles (uno escribe en el laptop, el otro dicta) y discuten sobre los temas de su interés que son tres: temas LGBT (2 grupos quieren trabajar con esta temática), migración (3 grupos) y bullying (3 grupos) (registro del diario de campo, Escuela ${ }^{\circ} 2$ ).

Por último, es posible afirmar que el proceso de representación fue coherente con las secuencias didácticas planificadas en la capacitación, por cuanto que el estudiantado representó cuatro temas según sus propios intereses: diversidad sexual, racismo, migración y bullying. Testimonios de estudiantes dan cuenta de que existe una vinculación entre las películas visionadas, el diálogo sostenido entre docentes y estudiantes y las producciones escolares como evidencia de la conexión establecida entre la realidad escolar - y personal con las ficciones visionadas:

Hacer una película muestra lo que pasa. Por ejemplo, alguien que molestaba a alguien por ser de otro color o de otra cultura, quizás al ver los videos cambia de opinión y se da cuenta que lo que estaba haciendo estaba mal y se pone a reflexionar sobre lo que hizo, se pone a pensar en lo malo (Estudiante, Escuela $n^{\circ} 5$ ).

Estudiante 2: también me gustó, es algo nuevo, interesante... uno nunca creyó que lo iba a hacer. Estudiante 1: A mí me encantó, en vez de estar escribiendo y después prepararse una semana para hacer una prueba. A mi gustó porque en la prueba tienes que rememorizar lo que tenías que hacer, acá no porque íbamos haciendo lo que aprendíamos. Estudiante 3: Aburre hacer pruebas, estar encerrados en la sala. Acá salíamos a grabar, a editar... (Estudiantes, Escuela $\left.n^{\circ} 4\right)$.

\section{CONCLUSIONES}

La implementación del visionado de cine, el diálogo y la reflexión en la enseñanza básica es un desafío complejo, pero, sin duda, necesario para avanzar en la enseñanza y desarrollo de competencias interculturales para la transformación de actitudes y conductas negativas como la discriminación, la xenofobia y el racismo. En este sentido constatamos la necesidad de fortalecer capacidades y habilidades del cuerpo docente para asumir liderazgo educativo disponibles en: https://www.youtube.com/channel/UCLp8fKtVrsbJ5AYImv6IXLA?view as=subscriber 
Mela-Contreras, J. (2020). Educación en competencias interculturales para la diversidad cultural, étnica y sexual. La experiencia del proyecto "Cineduka" en escuelas básicas chilenas. MODULEMA, 4, 24-41. DOI: http://dx.doi.org/10.30827/modulema.v4i015156

a través de acciones que le permitan conectar mejor con los intereses y problemáticas de sus educandos, así como estar mejor preparados para adaptar, flexibilizar e innovar en el currículo, de manera de propiciar estrategias y actividades de enseñanza desde un enfoque intercultural.

Entre los alcances pedagógicos de la propuesta encontramos el desarrollo de reflexiones, una perspectiva crítica y un gran estímulo para la actividad del diálogo entre pares estudiantes y el profesorado, competencias interculturales que posibilitan una mayor sensibilidad y respeto por la diferencia, elementos esenciales para reafirmar la democracia y la armonía social. La propuesta también permite reafirmar el ejercicio de la labor docente como esencial para interpelar al estudiantado sobre sus ideas y experiencias previas sobre la diversidad, potenciando relaciones entre nuevas ideas e informaciones, vinculadas a la aceptación y promoción de la diversidad cultural, étnica y sexual en el sistema escolar.

Constatamos, por ello, que la incorporación de herramientas del cine desde una perspectiva intercultural en la enseñanza básica, no solo facilita la construcción de climas de aprendizaje más participativos, y reflexivos, sino que también posibilita el desarrollo de competencias necesarias para avanzar en una educación inclusiva. En resumen, la experiencia de "Cineduka" permite generar recomendaciones para la implementación y desarrollo de metodologías no convencionales en el aula, así como releva la necesidad de desarrollar más investigaciones vinculadas al uso de las artes dentro del sistema educativo.

\section{REFERENCIAS BIBLIOGRÁFICAS}

Atkinson, D. (2018). Art, disobedience, and ethics. The adventure of pedagogy. Londres, UK: Palgrave Macmillan.

Berrios-Valenzuela, LI. \& Palou-Julián, B. (2014). Educación intercultural en Chile: la integración del alumnado extranjero en el sistema escolar. Educación y Educadores, 17(3), 405-426. Recuperado de: https://www.redalyc.org/pdf/834/83433781001.pdf

Colmenares-Escalona, A. \& Piñeiro-Martín, M. (2008). La investigación acción. Una herramienta metodológica heurística para la comprensión y transformación de realidades y prácticas socio-educativas. Laurus, 14(27), 96-114. Recuperado de: https://www. redalyc.org/articulo.oa?id $=76111892006$

Cornejo-Espejo, J. (2018). Discriminación y violencia homofóbica en el sistema escolar: estrategias de prevención, manejo y combate. Revista Brasileira de Educação, 23, 1-24. Recuperado de: http://www.scielo.br/scielo.php?script=sci_abstract\&pid=S1413$24782018000100224 \& \operatorname{lng}=e n \& n r m=i s o \& t \operatorname{lng}=e s$

Dysthe, O., Bernhardt, N, \& EsbjØrn, L. (2013). Enseñanza basada en el diálogo: el museo de arte como espacio de aprendizaje. Copenhague, Dinamarca: Skoletjenesten.

Donoso-Romo, A.; Contreras-Mühlenbrock, R.; Cubillos-Puelma, L. \& Aravena-Aragón, L. (2006). 
Mela-Contreras, J. (2020). Educación en competencias interculturales para la diversidad cultural, étnica y sexual. La experiencia del proyecto "Cineduka" en escuelas básicas chilenas. MODULEMA, 4, 24-41. DOI: http://dx.doi.org/10.30827/modulema.v4i015156

Interculturalidad y políticas públicas en educación. Reflexiones desde Santiago de Chile. Estudios Pedagógicos, 32(1), 21-31. Recuperado de: https://scielo.conicyt.cl/ scielo.php?script=sci_arttext\&pid $=$ S0718-07052006000100002

Ferrada-Torres, D. (2017). Formación docente para la diversidad. Propuestas desde la región del Biobío, Chile. RMIE, 22(74), 783-811. Recuperado de: http://www.scielo.org.mx/ scielo.php?script=sci_abstract\&pid=S1405-66662017000300783\&lng=es\&nrm=iso

Freire, P. (1970). Pedagogía del oprimido. México, CD, México: Siglo XXI editores, s.a.

Freire, P. (2004). Pedagogía de la autonomía. Sao Paulo, Brasil: Ediciones Paz e Terra, s.a. Recuperado de: https://www.buenosaires.gob.ar/areas/salud/dircap/mat/ matbiblio/freire.pdf

Freire, P. (2015). Pedagogía de la liberación. Barcelona, España: Ediciones La Catarata.

Gutiérrez-Bueno, B. \& Molina-García, M. (2019). El cine como herramienta para trabajar la diversidad cultural: investigación en aulas interculturales. Modulema, 3, 78-93. Recuperado de: https://digibug.ugr.es/handle/10481/56097

Ibáñez-Salgado, N. \& Druker-Ibáñez, S. (2018). La Educación Intercultural en Chile desde la perspectiva de los actores: Una co-construcción. Convergencia Revista de Ciencias Sociales, 78, 227-249. Recuperado de: https://convergencia.uaemex.mx/article/ view/9788

Instituto Nacional de Estadísticas (2019). Fichas comunales O'Higgins Tomo III: mapas de la inmigración internacional. Censo 2017. Recuperado de: https://regiones.ine. $\mathrm{cl} /$ documentos/default-source/region-vi/banco-datos-r6/resultados-censo-2017/ informe-con-fichas-comunales-o-higgins---tomo-3-mapas-de-la-inmigracióninternacional.pdf?sfvrsn=5984d4ed_4

Jiménez-Vargas, F. \& Fardella-Cisternas, C. (2015). Diversidad y rol de la escuela. Discursos del profesorado en contextos educativos multiculturales en clave migratoria. RMIE, 20(65), 419-441. Recuperado de: http://www.scielo.org.mx/scielo.php?script=sci arttext\&pid=S1405-66662015000200005

Lagos-Fernández, C. (2015). El programa de educación bilingüe y sus resultados: ¿perpetuando la discriminación? Pensamiento Educativo. Revista de Investigación Educacional Latinoamericana, 52(1), 84-94. doi: 10.7764/PEL.52.1.2015.7

Lifschitz-Javier, A. (2014). El audiovisual como forma de intervención social. Mediaciones Sociales, 13, 161-183. doi: 10.5209/rev_MESO.2014.n13.49436

McIntyre, A. (2008). Participatory action research. Los Ángeles, EE. UU.: Sage.

Ministerio de Educación (2009). Criterios y orientaciones de flexibilización del currículum para dar respuesta a la diversidad en los distintos niveles y modalidades de enseñanza. Informe final. Gobierno de Chile y Universidad Central. Recuperado de: https://especial.mineduc.cl/wp-content/uploads/sites/31/2016/08/Criterios Orientaciones_Flexibilizacion_Curricular-2009.pdf.

Ministerio de Educación (2011). PEIB-ORÍGENES: Estudio sobre la implementación de la Educación Intercultural Bilingüe. Recuperado de: http://peib.mineduc.cl/wpcontent/uploads/2018/05/Libro_publicacion_ed_20-09-2011.pdf 
Mela-Contreras, J. (2020). Educación en competencias interculturales para la diversidad cultural, étnica y sexual. La experiencia del proyecto "Cineduka" en escuelas básicas chilenas. MODULEMA, 4, 24-41. DOI: http://dx.doi.org/10.30827/modulema.v4i015156

Ministerio de Educación (2013) Discriminación en el contexto escolar - orientaciones para promover una escuela inclusiva. Recuperado de: http://www.movilh. cl/documentacion/educacion/Discriminacionenelespacioescolar-MineducMOVILH-2013.pdf

Ministerio de Educación (2017). Orientaciones técnicas para la inclusión educativa de estudiantes extranjeros. Recuperado de: https://www.ayudamineduc.cl/sites/ default/files/orientaciones-estudiantes-extranjeros-21-12-17.pdf

Meeus, J., González, R. \& Manzi, J. (2017). Ser “blanco” o “moreno” en Chile: el impacto de la apariencia en las expectativas educativas y las calificaciones escolares. En J. Manzi \& M. García (Eds.) Abriendo las puertas del aula: transformación de las prácticas docentes (pp. 515-542). Santiago, Chile: Ediciones UC.

Montero, M. (2006). Hacer para transformar: el método en la psicología comunitaria. Buenos Aires: Paidós.

ONU (2015). Comité de derechos Económicos, Sociales y Culturales (CESCR), Chile. Recuperado de: http://acnudh.org/24619/

Rozas-Poblete, M. (2019). Educación Intercultural Bilingüe en Chile. Definiciones y breve recuento histórico desde la década de 1990. Asesoría técnica parlamentaria. Biblioteca del Congreso Nacional de Chile. Recuperado de: https://www.bcn.cl/ obtienearchivo?id=repositorio/10221/27003/1/BCN_Poblete_EIB_definicion_y_ recuento_historico_final.pdf

Riedemann-Fuentes, A. (2008). La Educación Intercultural Bilingüe en Chile: ¿ampliación de oportunidades para alumnos indígenas? Revista Indiana, 25, 169-193. Recuperado de: $\quad$ https://www.iai.spk-berlin.de/fileadmin/dokumentenbibliothek/Indiana/ Indiana_25/Indiana_25_169-193_Riedemann.pdf

Skidmore, D. \& Murakami, K. (ed) (2016). Dialogic Pedagogy: The Importance of Dialogue in Teaching and Learning. Bristol: Multilingual matters.

Stefoni-Espinoza, C.; Stang-Alva, F. \& Riedemann-Fuentes, A. (2016). Educación e interculturalidad en Chile: un marco para el análisis. Estudios Internacionales, 48(185), 153-182. Recuperado de: https://scielo.conicyt.cl/scielo.php?script=sci_ arttext\&pid=S0719-37692016000300008

Treviño, E.; Morawietz, L.; Villalobos, C. \& Villalobos, E. (2018). Educación intercultural en chile: experiencias, pueblos y territorios. Santiago: Ediciones UC.

Universidad Nacional de Colombia, Cátedra UNESCO (2017). Competencias interculturales. Marco conceptual y operativo. Recuperado de: https://unesdoc.unesco.org/ ark:/48223/pf0000251592

Fondo de las Naciones Unidas para la Infancia (2014a). La Voz de los Niños, Niñas y Adolescentes y Discriminación. Recuperado de: http://www.unicef.cl/web/wp- content/uploads/ doc_wp/PPT\%20La\%20Voz\%20Discriminacion\%202011\%20final.pdf

Fondo de las Naciones Unidas para la Infancia (2014b). Annual Report 2014. Chile. Recuperado de: https://www.unicef.org/about/annualreport/files/Chile_Annual_Report_2014. pdf 
Mela-Contreras, J. (2020). Educación en competencias interculturales para la diversidad cultural, étnica y sexual. La experiencia del proyecto "Cineduka" en escuelas básicas chilenas. MODULEMA, 4, 24-41. DOI: http://dx.doi.org/10.30827/modulema.v4i015156

\begin{tabular}{ll}
\hline Autores / Authors & Saber más / To know more \\
\hline José Mela Contreras & D $0000-0003-1192-4519$ \\
Investigador y académico del Instituto de Ciencias de la & \\
Educación (Iced) de la Universidad de O’Higgins. Doctor en & \\
Artes y Educación de la Universidad de Barcelona y Máster \\
en Educación Interdisciplinar de las Artes de la misma casa \\
de estudios. Licenciado en artes con mención en pintura \\
y Profesor de Artes Plásticas de la de la Universidad de \\
Chile. En el ámbito artístico ha desarrollado diferentes \\
proyectos artísticos vinculados con la identidad chilena e \\
indígena, dentro y fuera de Chile. En el área académica \\
ha desarrollado proyectos relacionados con la Educación \\
Artística, la identidad y la educación intercultural en \\
diferentes niveles educativos. Asimismo, ha estado ligado \\
con proyectos de investigación multi e interdisciplinares \\
con otras disciplinas, tales como la antropología.
\end{tabular}

